\title{
QUEIMA CONCOMITANTE DE BIOMASSA E COQUE DE PETROLEO EM CALDEIRA LEITO FLUIDIZADO CIRCULANTE*
}

\author{
Wagner da Silva Lima ${ }^{1}$ \\ Rodrigo Alberto Moreira Gomes ${ }^{2}$ \\ Flavio Marques de Queiroz ${ }^{3}$ \\ Gabriel Augusto Gomes ${ }^{4}$ \\ Ebenezer Gomes Cavalcanti Neto ${ }^{5}$ \\ Luiz Flávio da Silva ${ }^{6}$ \\ Antonio Rimaci ${ }^{7}$ \\ Francisco Cézar Freire ${ }^{8}$
}

\section{Resumo}

Um Sistema Piloto de alimentação de biomassa foi instalado em paralelo ao sistema de alimentação de coque em uma caldeira leito fluidizado circulante movida a coque de petróleo na Unidade Fabril da Votorantim Metais em Niquelandia, GO. Quatro experimentos foram realizados utilizando os alimentadores de coque (limitados a capacidade de mistura da pá-carregadeira) e o sistema piloto instalado que tem capacidade de $30 \mathrm{~m}^{3} / \mathrm{h}$ de cavaco de eucalipto. A substituição energética chegou a $19 \%$, bem acima dos $10 \%$ determinados pelo fabricante utilizando o sistema atual de alimentação de combustível na caldeira. O potencial de redução de custo do vapor varia de 4 a $7 \%$.

Palavras-chave: Geração de vapor; Leito fluidizado; Energia renovável; Biomassa.

\section{COFIRING PETCOKE AND BIOMASS IN A CIRCULATING FLUIDIZED BED BOILER}

\begin{abstract}
A biomass feeder pilot system was installed in parallel to the actual coke supply system in a circulating fluidized bed boiler fueled by petroleum coke in a Votorantim Metals nickel facility in Niquelândia, GO. Four experiments were conducted using petcoke feeders (limited to loader machine ability) and the pilot system installed which has a capacity of 30 cubic meters per hour of eucalyptus wood chips. Energy substitution reached $19 \%$, well above the $10 \%$ determined by the manufacturer using the current system of fuel supply to the boiler. The steam cost potential reduction ranges from 4 to $7 \%$.
\end{abstract}

Keywords: Steam generation; Fluidized bed; Renewable energy; Biomass.

1 Engenheiro eletricista, Doutor, Consultor de energia, Diretoria de tecnologia/Gerência de inovação e tecnologia energia, Votorantim Metais, São Paulo, SP, Brasil.

2 Engenheiro mecânico, Mestre, Gerente de Inovação e Energia, Diretoria de tecnologia/Gerencia de inovação e tecnologia energia, Votorantim Metais, Belo Horizonte, MG, Brasil.

3 Engenheiro eletricista, Graduado, Gerente Utilidades, VM - UF NQL, Niquelândia, GO, Brasil.

4 Engenheiro eletricista, Graduado, Coordenador Utilidades, VM - UF NQL, Niquelândia, GO,

5 Engenheiro mecânico, graduado, Consultor Área Desenvolvimento de Produtos e Processos Industriais/ SENAI CIMATEC DR/BA, Salvador, BA, Brasil.

6 Engenheiro mecânico, graduado, Consultor Área Desenvolvimento de Produtos e Processos Industriais/ SENAI CIMATEC DR/BA, Salvador, BA, Brasil.

7 Engenheiro químico, especialista, Consultor Área Desenvolvimento de Produtos e Processos Industriais/ SENAI CIMATEC DR/BA, Salvador, BA, Brasil.

8 Engenheiro químico, Graduado, Gerente de Processos Químicos, Área de Tecnologia e Processos, SENAI CIMATEC DR/BA, Salvador, BA, Brasil. 


\section{INTRODUÇÃO}

A unidade fabril de Niquelândia no Estado de Goiás da Votorantim Metais é um complexo industrial inaugurado em 1981 formado por mina a céu aberto de minério de níquel e usina de processamento que produz carbonato de níquel ( $\mathrm{CbNi}$ ) a partir da moagem, secagem, redução (fornos Herreshoff), lixiviação amoniacal, torres de evaporação e secagem de carbonato.

O vapor é utilizado principalmente para a lixiviação amoniacal e para as torres de evaporação de lama, conforme pode ser visto na Tabela 1 abaixo:

Tabela 1. Uso final do vapor na Unidade Niquelandia.

\begin{tabular}{|l|l|r|c|}
\hline & \multicolumn{1}{|c|}{ USO FINAL } & $\begin{array}{r}\text { DEMANDA } \\
\text { tph }\end{array}$ & \\
\hline 1. & Secagem e moagem & 4,0 & $2,5 \%$ \\
\hline 2. & Redução (Aquecimento de óleo) & 14,0 & $8,8 \%$ \\
\hline 3. & Hidrometalurgia (lixiviação e torres evap.) & 106,2 & $66,4 \%$ \\
\hline 4. & Utilidades (Back-up caldeiras e desaerador) & 35,8 & $22,4 \%$ \\
\hline \multicolumn{2}{|r|}{ TOTAL } & $\mathbf{1 6 0 , 0}$ & $\mathbf{1 0 0 \%}$
\end{tabular}

A demanda de vapor total da planta industrial e de consumo próprio da área de utilidades é da ordem de 160 toneladas de vapor por hora (tph). A geração de vapor até 2009 era realizada através de quatro caldeiras à óleo em baixa pressão (7 bar).

Devido ao consistente aumento do preço do óleo combustível 2A e a pressão sobre os custos do CbNi a VM avaliou em 2006 a outras possibilidades como a instalação de uma caldeira a biomassa (devido à disponibilidade de florestas próprias) e também ao uso de coque de petróleo (Devido ao já bem-sucedido uso deste combustível pela Votorantim Cimentos - VC e outras companhias cimenteiras no mundo [1]). A opção vendedora foi a instalação de uma caldeira à coque de 200 tph com a tecnologia de leito fluidizado circulante. Atualmente é a única caldeira desta tecnologia com uso de coque de petróleo como combustível no Brasil.

A pressão da caldeira comprada da finlandesa Foster-Wheeler foi de 65 bar. A temperatura do vapor de saída é de 405 C. O vapor de alta pressão alimenta uma turbina de contra-pressão de $16 \mathrm{MW}$ que fornece $57 \%$ da demanda de eletricidade da planta.

Esta caldeira CFB 200 tph, segundo o fabricante, foi projetada para queimar em cofiring o coque com até $10 \%$ de cavaco de madeira com até $50 \mathrm{~mm}$ de granulometria e umidade até 35\% [2].

A VM já vinha processando (corte, colheita e picagem) de uma antiga floresta anteriormente destinada à produção de carvão vegetal (para uso na redução de minério de níquel). O custo energético deste cavaco de eucalipto no galpão de coque foi verificado em $37 \%$ menor que o do coque em $R \$$ por Gcal.

Foi realizado um Projeto de P\&D via EMBRAPII para a realização de experimentos foram realizados de misturas de coque e biomassa tanto via sistema de alimentação de coque (limitado à $10 \%$ de mistura em energia) e através da instalação de um Sistema Piloto de Alimentação de Biomassa, que operou em paralelo ao sistema de alimentação de coque.

Este artigo descreve o Sistema Piloto de Alimentação de Biomassa, o aprendizado e os resultados obtidos. 


\section{MATERIAIS E MÉTODOS}

\subsection{Coque de Petróleo [3]}

O coque de petróleo é um sólido carbonoso derivado de coquerias em refinarias de petróleo ou outros processos de craqueamento. Sua composição básica é de carvão elementar (usualmente acima de $85 \%$, base seca). O mais atrativo neste combustível é seu elevado poder calorífico e baixo teor de cinzas. O coque de petróleo é um combustível competitivo (Cerca de 50-60 US\$ nas refinarias do Golfo do México e já muito utilizado em projetos de caldeiras CFB (Leito fluidizado circulante).

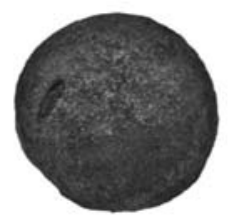

Figura 1. Grão de coque de petróleo

Existem dois tipos básicos de coque de petróleo. O coque fluido (ou coque fino) e o delayed coke. O coque fluido tem conteúdo de voláteis na ordem de $5 \%$ e devido ao pequeno tamanho de suas partículas não adequado para a queima em caldeiras CFB. O delayed coke contém 8 a 15\% de voláteis e teor de enxofre na faixa de 3 a $8 \%$, embora alguns coques deste tipo podem ter teor de enxofre menor que $1 \%$.

Devido ao baixo teor de cinzas um material adicional solido no leito é necessário. Os metais pesados contidos nas cinzas contem vanádio e níquel na ordem de 500 e 3.000 ppm respectivamente. Coque com teor de vanádio acima de 10.000 ppm também é possível.

Logo o abatimento de enxofre com calcário resolve os problemas da geração de $\mathrm{SO}_{\mathrm{x}}$ na queima e do material solido adicional no leito.

O enxofre é abatido para cumprimento da legislação ambiental com calcário, formando gesso. O coque utilizado pela VM em Niquelândia apresenta teor médio de enxofre de $6 \%$ e $0,5 \%$ de cinzas. Para o abatimento de enxofre utiliza-se em média $35 \%$ em peso (base úmida) de calcário.

O gesso produzido é certificado pelo MAPA (Ministério da Agricultura, Pecuária e Abastecimento) para uso agrícola e é comprado por um terceiro que aloca o mesmo no mercado nacional para agricultura.

A umidade do coque varia de 5 a 10\%. A granulometria adequada a caldeira varia de 20 a $3 \mathrm{~mm}$. Em particular a caldeira de VM-NQL utiliza uma mistura do coque alto teor de enxofre $(6 \% \mathrm{~S})$ com um mais fino comprado no mercado nacional com $1 \% \mathrm{~S}$ (coque baixo teor) para formar um blend ou mistura com média de $5 \%$ de enxofre.

Tabela 2. Análise típica do coque de petróleo (green delayed petcoke)

\begin{tabular}{|l|c|c|l|}
\hline VARIÁVEL & MÍNIMO & MÁXIMO & UNIDADE \\
\hline Umidade & 2 & 10 & $\%$ \\
\hline Cinzas & 0,3 & 5,0 & $\%$ \\
\hline Voláteis & 8 & 15 & $\%$ \\
\hline PCI & 22 & 33 & $\mathrm{MJ} / \mathrm{kg}$ \\
\hline Enxofre & 3 & 8 & $\%$ \\
\hline Vanádio & 500 & 3.000 & $\mathrm{ppm}$ \\
\hline
\end{tabular}




\subsection{Cavaco de Madeira}

A biomassa (cavaco de eucalipto), por sua vez, é um combustível renovável provinda de floresta comercial plantada para suprimento de energia para uso industrial.

A caldeira a coque tem capacidade de $200 \mathrm{tv} / \mathrm{h}$. A utilização normal dela atualmente é de $160 \mathrm{tv} / \mathrm{h}$ (80\% do MCR). A Foster-Wheeler (FW) apresenta no Manual da Caldeira o potencial de se utilizar até $10 \%$ em energia de cavaco de eucalipto substituindo coque no MCR (200 tv/h) utilizando o próprio sistema de alimentação de coque da caldeira.

Simulações computacionais realizadas em 2011 apontaram potencial de substituição de até $16 \%$ em energia de coque por cavaco de eucalipto. Em massa isto daria uma substituição de $24,8 \%$ em peso.

O cavaco de eucalipto é originário de florestas residuais (com 22 anos de idade) da própria VM situadas a cerca de $50 \mathrm{~km}$ de distância do galpão de coque. A Figura 2 apresenta as toras de eucalipto, o picador móvel e cavaco de eucalipto.

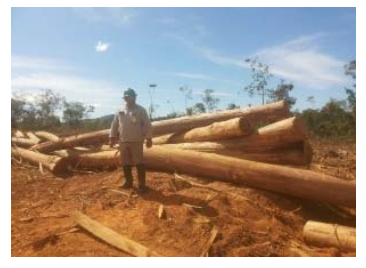

(a)

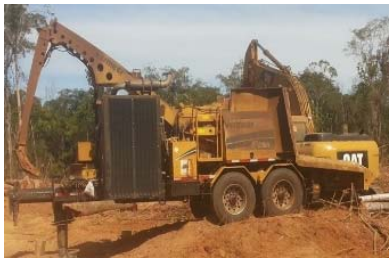

(b)

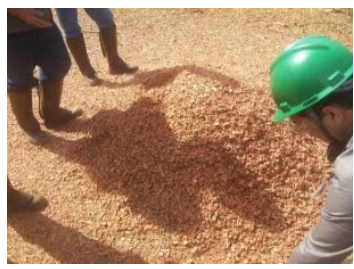

(c)

Figura 2. Toras, cavacos de madeira para os experimentos

A Tabela 3 apresenta as características principais do cavaco de eucalipto utilizado.

Tabela 3. Análise química imediata do cavaco de eucalipto e do coque

\begin{tabular}{|l|c|c|l|}
\hline \multicolumn{1}{|c|}{ VARIÁVEL } & COQUE & CAVACO & UNIDADE \\
\hline Umidade & 8,0 & 35,0 & $\%$ \\
\hline Cinzas & 0,25 & 0,61 & $\%$ \\
\hline Voláteis & 9,75 & 52,82 & $\%$ \\
\hline Carbono fixo & 82,00 & 11,57 & $\%$ \\
\hline PCI & 7,950 & 2,675 & $\mathrm{Gcal} / \mathrm{t}$ \\
\hline Gramulometria & $3-20$ & $5-50$ & $\mathrm{~mm}$ \\
\hline Densidade & 840 & 345 & $\mathrm{~kg} / \mathrm{m}^{3}$ \\
\hline
\end{tabular}

\subsection{Sistema Piloto de Alimentação de Biomassa}

O coque de petróleo armazenado no galpão de coque é alimentado nas moegas através de pá-carregadeira. Destas moegas o coque chega a um elevador de canecas que através de dois shoots chega ao silo de coque com capacidade de armazenamento para 12 horas.

A caldeira a coque tem quatro alimentadores que por gravidade leva o coque até a fornalha da caldeira. A Foster-Wheeler no Manual da Caldeira sugere a alimentação de biomassa independente do sistema de alimentação de coque como mostra a Figura 3. Além disso, o sistema de biomassa deve ser conectado aos dois alimentadores centrais de coque. 


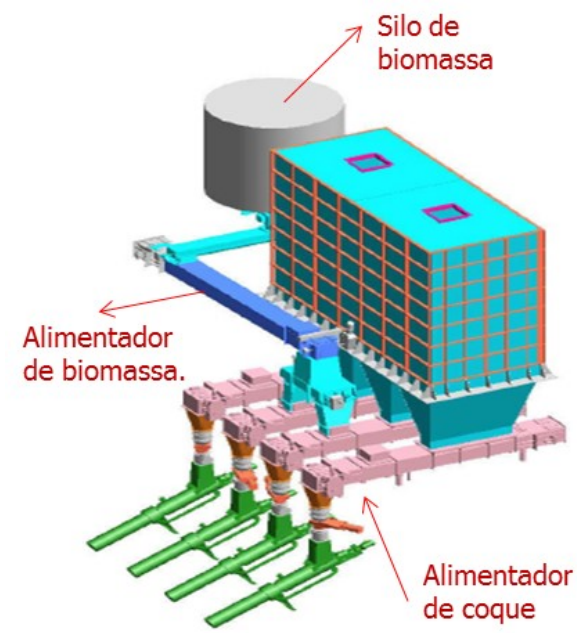

Figura 3. Forma de alimentação de biomassa proposto no manual da Foster-Wheeler

Foi verificado que a estrutura do silo de coque da caldeira não teria condições estruturais de suportar um silo de biomassa. Em decorrência disto o Sistema Piloto de Alimentação de Biomassa não contempla o uso de silo de biomassa. A Figura 4 apresenta o Sistema Piloto de Alimentação de Biomassa proposto.
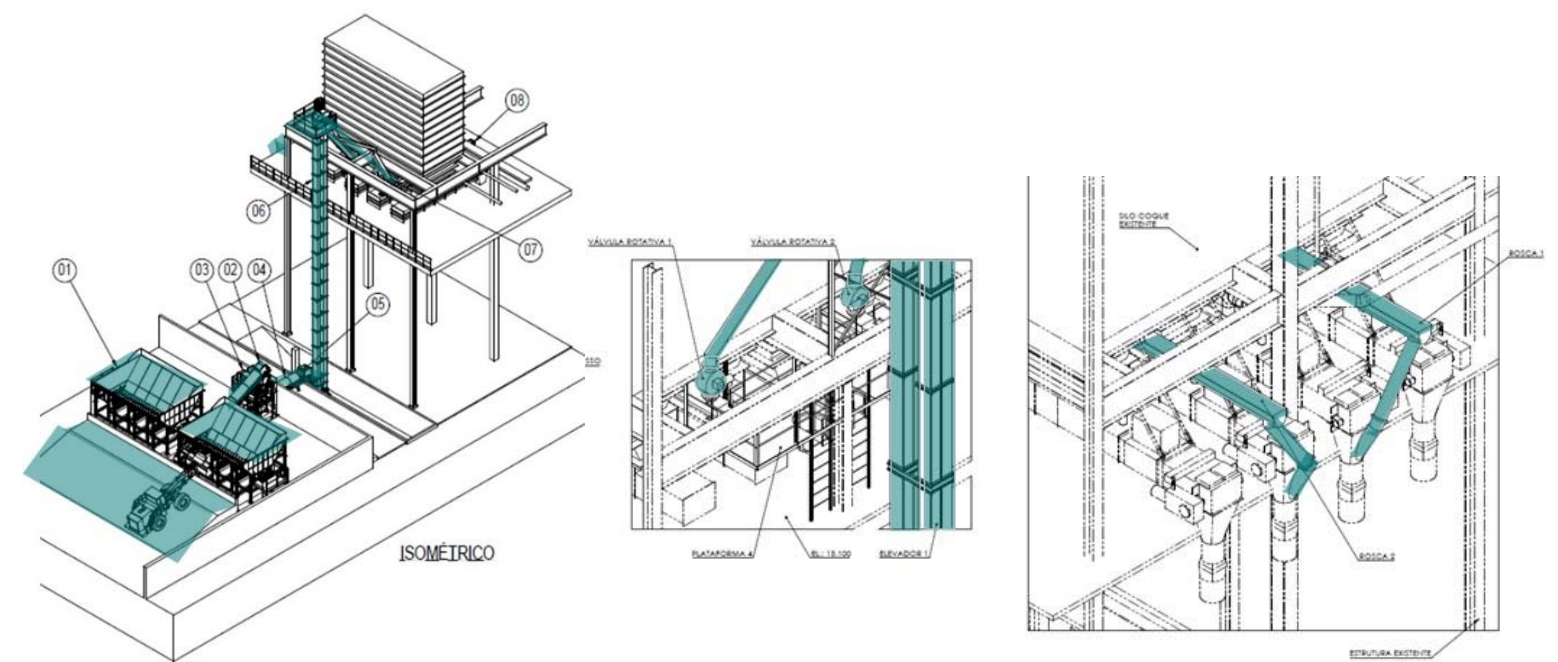

Figura 4. Sistema Piloto de Alimentação de Biomassa proposto para os experimentos (em azul)

Esta estrutura foi instalada no galpão de coque. As moegas (1) perfazendo um total de $100 \mathrm{~m}^{3}$ (para compensar a falta do silo) alimentam (acionadas por inversor de frequência) uma esteira (3) que leva a um classificador de biomassa e detector de metais (2). A esteira (4) alimenta o elevador de canecas (5) com capacidade de $30 \mathrm{~m}^{3}$ por hora. Do elevador de canecas descem duas tubulações até as roscas rotativas dosadoras (6). As roscas dosadoras têm função de alimentação continua das roscas sem fim (7) alimentadoras da transição (8) para o sistema de alimentação de coque na descida do mesmo (à esquerda Figura 4). 


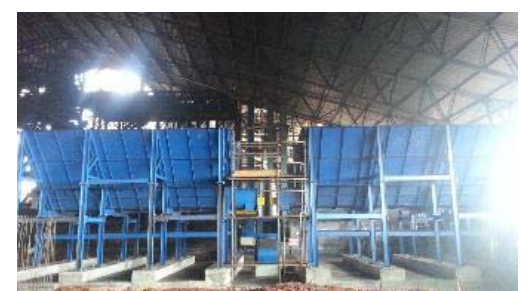

(a)

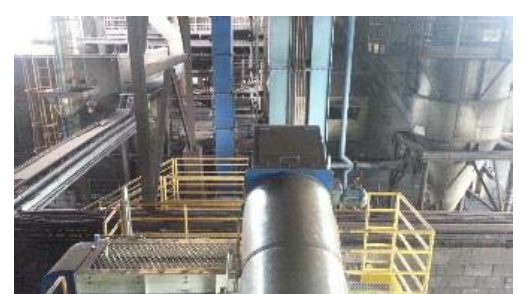

(b)

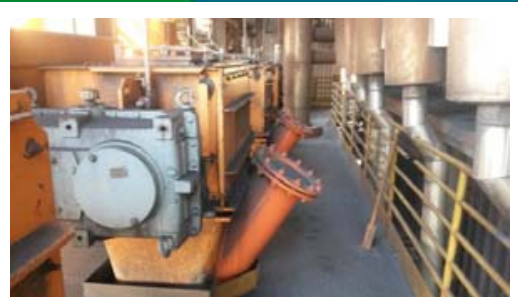

(c)

Figura 5. Moegas de biomassa, detector de metais, shoots para conexão da alimentação da biomassa para a alimentação de coque

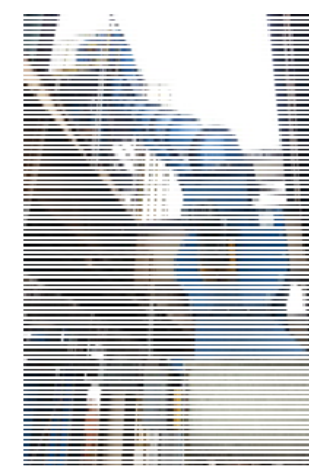

Figura 6. Rosca rotativa dosadora

Para supervisão e controle foi desenvolvido pelo SENAI-BA um programa computacional especifico para controle do Sistema Piloto. Não foi necessária a alteração do sistema supervisório da caldeira a coque.

\section{RESULTADOS E DISCUSSÃO}

\subsection{Experimentos com Sistema de Alimentação de Coque}

Foram realizados quatro experimentos. Dois preliminares utilizando o sistema de alimentação de coque (silo e correias transportadoras) fazendo um blend de coque e biomassa (Ver Figura 7).

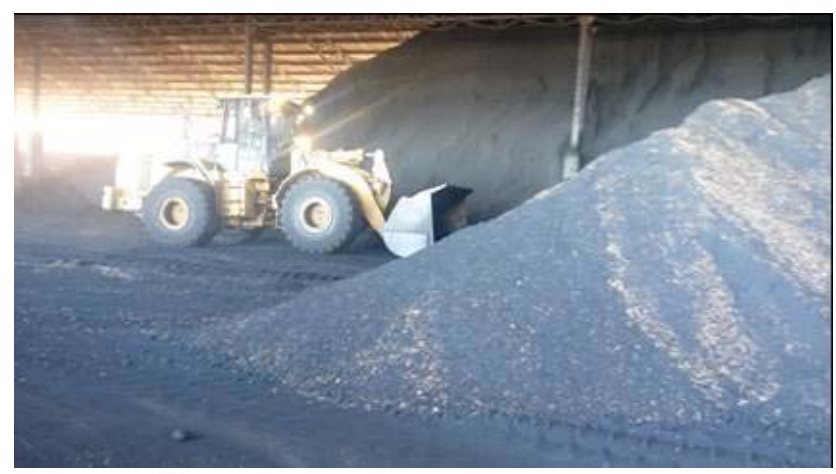

Figura 7. Blend coque e biomassa

Foram realizadas misturas de 3,5\% e 6,5\% em energia. O limite em 6,5\% é devido ao limite da mistura realizada pela pá carregadeira. Este experimento que durou 72 horas permitiu aos operadores da caldeira verificar as variações de velocidade da esteira de coque (em função de um combustível menos denso), dos efeitos da temperatura do leito que em um primeiro momento teve redução de temperatura. 
Para resolver o problema o ar primário ou de fluidização foi reduzido voltando à temperatura normal. $\mathrm{O}$ ar primário ficou na mesma vazão utilizada somente com o coque. O coque é um combustível com baixo teor de oxigênio (1\%). A biomassa contém cerca de $49 \%$ de seu peso é oxigênio sendo assim uma oferta complementar do oxigênio estequiométrico permitindo uma vazão menor do ar-primário.

Um dos efeitos percebidos neste experimento foi que o coque fino (baixo teor de enxofre) que não era queimado devido sua granulometria passou a ter queima completa como pode ser observado na Figura 8. Isto se deveu ao aumento da radiação térmica no meio da fornalha em função da queima de voláteis da biomassa nesta região.

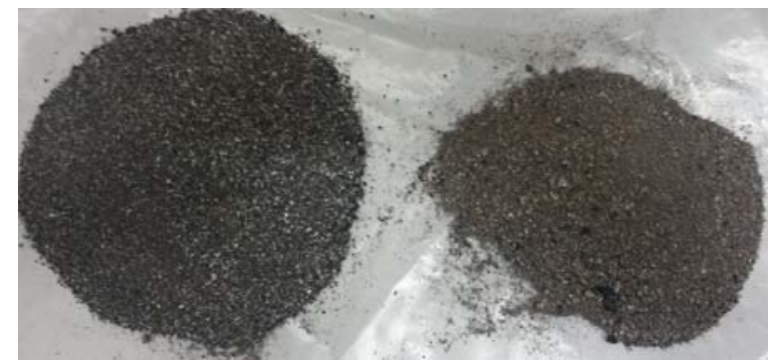

Figura 8. Cinzas pesadas (bottom ash) sem cofiring (a esquerda) e com cofiring (à direita)

Constatada a estabilidade da operação foi programado mais um experimento. Este segundo experimento teve duração de 89 dias o cofiring chegou a 8,5\% (valor estimado) de substituição energética. A principal variável observada pelos operadores é o rendimento da caldeira dado monitorado no supervisório da mesma. Neste supervisório o rendimento é entendido como razão entre a produção de vapor (tvph) e a vazão de combustível (tph). Assim, o rendimento é quantidade de vapor produzida por tonelada de combustível. A Figura 9 apresenta o rendimento da caldeira durante os testes.

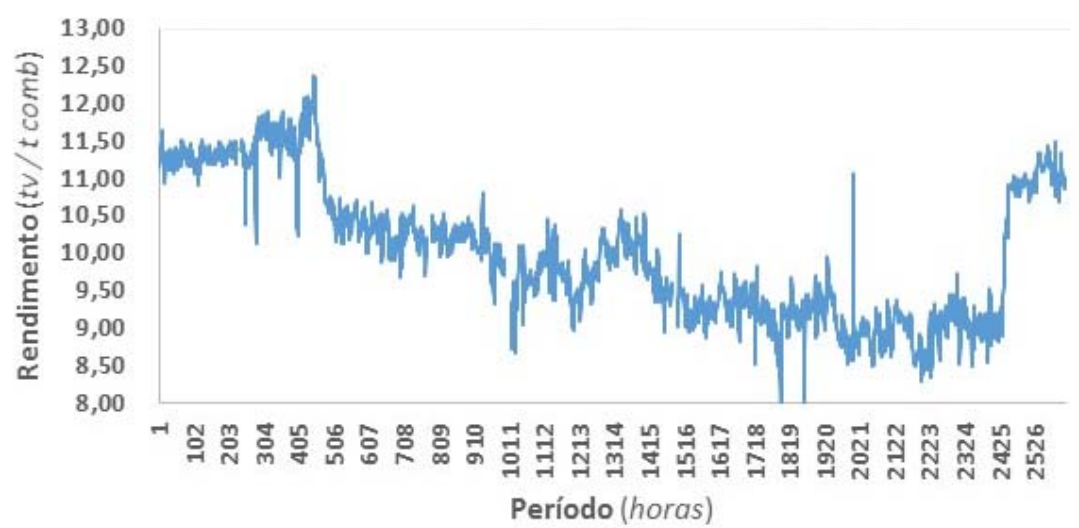

Figura 9. Experimento 2 - Rendimento da caldeira a coque (Biomassa alimentada nas moegas de coque)

A dificuldade encontrada em determinar a correta taxa de substituição de coque por biomassa provem da falta de células de carga (medição de vazão mássica) nas esteiras de coque. Ou seja, a quantidade exata de coque e biomassa que alimentou a caldeira não pode ser determinada com a exatidão necessária para se apurar os ganhos. A mesma dificuldade é relatada em [4]. 


\subsection{Experimentos com Sistema Piloto}

O Sistema Piloto de Alimentação de Biomassa descrito na Seção 2, tem células de carga para medição mássica nas duas roscas sem fim de biomassa. Assim foi possível determinar a vazão mássica da mesma. O supervisório da caldeira determinou a vazão de coque.

O primeiro experimento com o Sistema Piloto de Alimentação de Biomassa foi realizado num período em 10 horas e 35 minutos. Este experimento permitiu aos operadores acostumar com as variações de temperatura do leito devido à introdução de biomassa que contém mais voláteis e oxigênio em sua constituição. Devido a não existência do silo, e subestimada vazão de cavaco, houveram momentos de falta de biomassa para alimentação do sistema. Isto pode ser observado nos picos de alimentação de coque durante este terceiro experimento na Figura 10. Apesar da instabilidade da operação a substituição média foi de $8,1 \%$ de substituição energética.

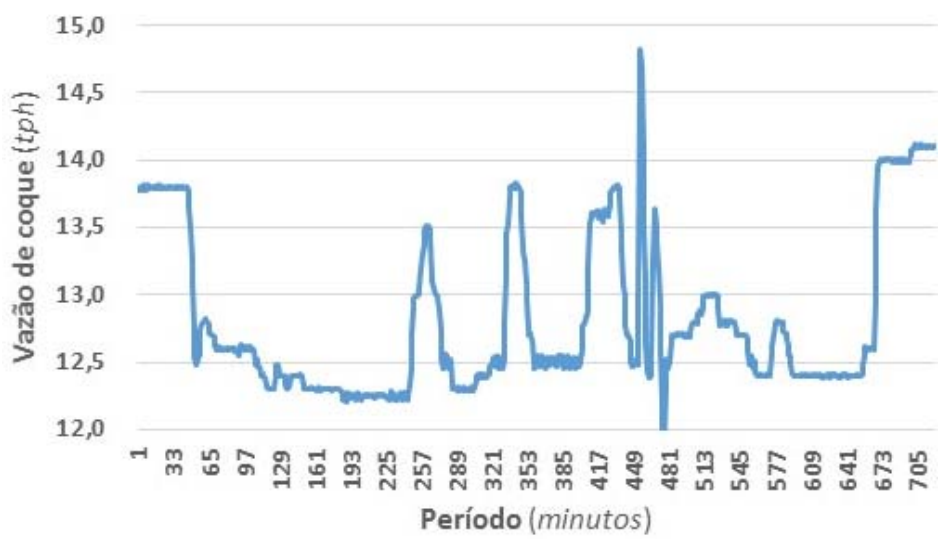

Figura 10. Vazão de coque durante para o $1^{\circ}$ experimento com Sistema Piloto (Experimento 3)

Uma vez melhorada a coordenação da movimentação da pá-carregadeira um novo experimento foi realizado. Desta vez o Sistema Piloto e a caldeira funcionaram de maneira estável por 7 horas. A Figura 11 apresenta a vazão de coque durante 0 experimento 4.

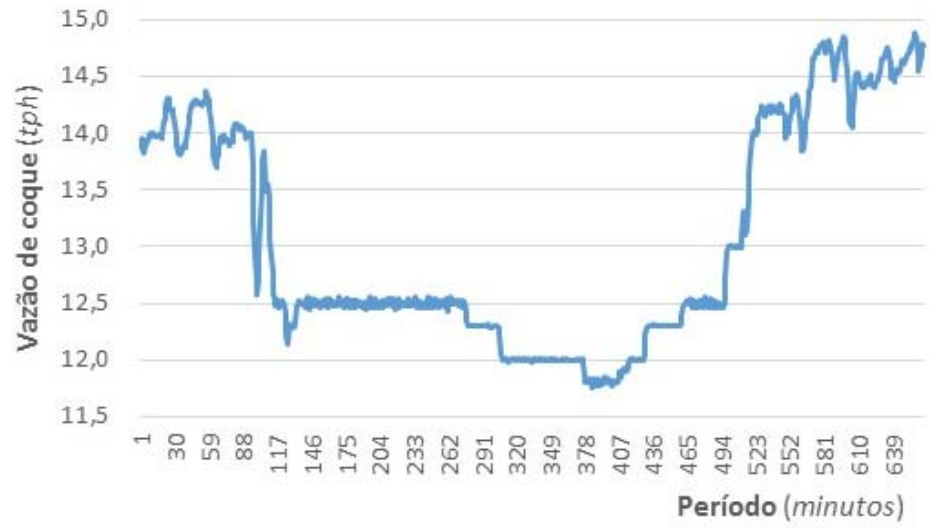

Figura 11. Vazão de coque durante para o $2^{\circ}$ experimento com Sistema Piloto (Experimento 4) 
Tabela 4. Resultado dos experimentos com o Sistema Piloto de Alimentação de Biomassa

\begin{tabular}{cccccccc}
\hline Teste & $\begin{array}{c}\text { Rendimento } \\
\text { Ajustado } \\
\text { Combustivel } \\
t v / t \text { comb }\end{array}$ & $\begin{array}{c}\text { Vazão } \\
\text { Vapor }\end{array}$ & $\begin{array}{c}\text { Vazão } \\
\text { Ajustada } \\
\text { Coque }\end{array}$ & $\begin{array}{c}\text { Vazão } \\
\text { Medida } \\
\text { Coque } \\
t p h\end{array}$ & $\begin{array}{c}\text { Substituição } \\
\text { Energética } \\
\text { Gcal } \\
\%\end{array}$ & $\begin{array}{c}\text { Vazão } \\
\text { Cavaco }\end{array}$ & \\
\hline $\mathbf{3}$ & 11,05 & 152,1 & 13,76 & 12,65 & $8,1 \%$ & 3,31 & 9,6 \\
\hline $\mathbf{4}$ & 10,84 & 156,1 & 14,40 & 12,37 & $14,1 \%$ & 6,05 & 17,5 \\
\hline
\end{tabular}

A tabela acima considera a variabilidade do rendimento com a geração de vapor, como pode ser observado na Figura 12 abaixo.

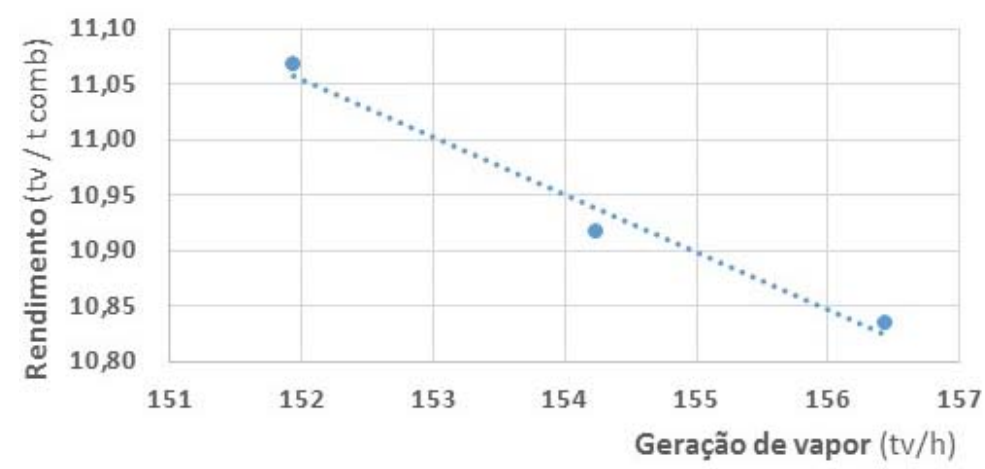

Figura 12. Variação do rendimento em função do despacho de vapor da caldeira

Logo, o sistema de alimentação independente de biomassa permitiu um nível de cofiring estável e controlável de $8 \%$ a quase 14\% (com pico de 19\%). Entretanto, houve diversas dificuldades com a rosca rotativa por problemas de travamento. $O$ fabricante fez as modificações necessárias para sanar o problema.

\section{CONCLUSÃO}

A Foster-Wheeler, fabricante da caldeira, determinou o máximo de substituição energética na caldeira CFB da VM em Niquelândia em $10 \%$. Através de simulações e de avaliação de alternativas de alimentação de cavaco de eucalipto, conseguiu-se substituição energética através de um Sistema Piloto de Alimentação de Biomassa paralelo ao atual sistema de alimentação de combustível atual.

A substituição de até $14 \%$ de coque permite um ganho de até $5 \%$ no custo do vapor. Além disso, representa uma redução de 88 mil toneladas equivalentes de $\mathrm{CO}_{2}$, melhorando a performance ambiental da planta e gerando emprego e renda na região (corte, colheita, picagem e transporte de biomassa). Com o Sistema Piloto de Alimentação de Biomassa foi possível chegar a substituições de 8 a $14 \%$ de forma controlável e estável.

\section{Agradecimentos}

Á EMBRAPII (Empresa Brasileira de Pesquisa e Inovação Industrial) co-financiamento de $50 \%$ dos custos deste projeto de pesquisa aplicada em área industrial de produção da Votorantim Metais. 


\section{REFERÊNCIAS}

1 Royo, J, Canalis, P., Sevastián, F, Gómez, M. Enviromental feasibility of biomassa cofiring in the cement industry. Results of the tests carried out at the CEMEX company plant located in Morata de Jalón (Spain). Presented to 15th European biomass conference. 7 - 11 2007, Berlin, Germany.

2 Palmu, A. Performance Engineering - Coke firing. Foster-Wheeler. Finland. 2009. 6 p.

3 Nuortimo, K, Lampenius, H, Khryashcheva, A, Boensel, T. The CFB technology benefits in comparison with conventional solid fuel generation technologies for utility and cogeneration applications. Presented at Russia Power seminary. 5-6 March 2013. Moscow, Russia. 21 p.

4 Barletta D, Diaz A, Esposito, L, Montenegro, L, Sanchez, JM, Poletto M.

Characterisation of flow properties of coal-petcoke-biomass mixtures for cofiring. Chemical Engineering Transactions, 2013; Vol. 32: 1525-1530. 